Davis, G. H. G. (1960). J. gen. Microbiol. 22, 740-743

\title{
The Interpretation of Certain Morphological Appearances in a Streptomyces sp.
}

\author{
By G. H. G. DAVIS \\ Department of Bacteriology, University of Birmingham
}

SUMMARY: Branches of the primary mycelium of a Streptomyces sp. were observed, by phase-contrast microscopy of living material, to form apparent anastomoses. No enlarged structures capable of interpretation as 'initial cells' were detected. It is suggested that certain of the large 'spore-like bodies' described by previous workers in studies upon Streptomyces spp. may represent protoplasts.

The life cycle proposed by Klieneberger-Nobel (1947) to explain nuclear and cytological appearances in Streptomyces species is briefly as follows. Spore germination by one or more germ tubes produces a slender much branched primary mycelium in and upon the substrate. Cellular fusion between branches of this mycelium, followed by nuclear fusion to yield a diploid 'initial cell', is then proposed to explain the origin of a diploid secondary aerial mycelium, the cytological appearance of which differs considerably from that of the primary mycelium. Spore formation at the extremities of the aerial hyphae is preceded by a nuclear reduction division giving once more haploid spores.

An essential feature of this scheme is the fusion of cells and of nuclei in the primary mycelium. As pointed out by Bisset (1955) the details of this process have not been adequately described. The occurrence of cellular fusion, 'initial cells' and nuclear exchange are in fact all subjects of controversy (Davis, 1959).

Klieneberger-Nobel (1947) described tangled 'nests' of primary hyphae and suggested that fusion occurred at these sites. Carvajal (1946) observed by electron microscopy apparent fusion between hyphae and between young germination tubes in Streptomyces griseus. Nest formation was described by Baldacci, Gilardi \& Amici (1956) in the primary mycelium, and Dickenson \& MacDonald (1955) claimed to demonstrate fusion in primary mycelium, without nest formation, by electron microscope observations. However, Erikson $(1949,1955)$ stated that fusion between primary mycelial elements never occurs, and that in fact growing hyphae avoid contact with each other under normal conditions. Gregory (1956) demonstrated apparent hyphal anastomosis by cell-wall staining techniques, although his illustrations do not prove beyond doubt that the cell walls at the point of hyphal contact were broken to form a truly anastomosing system. By using ultra-thin sections Stuart (1959) obtained beautiful photographs of mycelial branching and nuclear arrangements but was unable to detect any signs of anastomosis. These reports, all based upon observations of non-living material, therefore permit a variety of conclusions about the occurrence of cellular fusion. 
Similarly, the structures which have been interpreted as possible 'initial cells' have been variously described (McGregor, 1954). Gregory (1956) suggested that 'initial cells' are not formed, but that the secondary mycelium arises from the primary as the result of physiological rather than nuclear changes. Gregory did, however, describe some indeterminate large structures at the extremities of certain hyphae.

Evidence which appears to support the nuclear cycle proposed by Klieneberger-Nobel has come from genetical studies (Bradley \& Lederberg, 1956; Bradley, 1957; Sermonti \& Spada-Sermonti, 1956). These workers demonstrated the transfer of characters between Streptomyces strains; this in itself does not prove nuclear or cytoplasmic fusion but may be the result of some other mechanism (Bradley, 1958).

During studies of the morphology of various members of the order Actinomycetales the material presented in this note was obtained and appeared relevant to the questions discussed above.

\section{METHODS}

For observing mycelial anastomosis in Streptomyces. Spores of Streptomyces spp. isolated from soil were inoculated into a drop of semi-solid nutrient agar on a glass slide. A ring of paraffin wax about $1 \mathrm{~mm}$. thick had previously been built upon the slide around the area supporting the agar, and after inoculation a sterile cover-glass was placed over the agar and heated gently with a wire loop to fuse it to the wax ring. The inoculated agar thus formed a central island in contact with cover-glass and slide, and surrounded by an air space enclosed by the wax. Such microcultures were mounted upon a phase-contrast microscope equipped with a $35 \mathrm{~mm}$. camera attachment; the whole apparatus was incubated at $28^{\circ}$.

For observing an unusual cytological appearance in Nocardia asteroides. Nocardia asteroides (NCTC. 8595) is very streptomyces-like in many respects. In the present work spores were inoculated upon sterile cellophan disks on the surface of nutrient agar containing also $0.3 \%(\mathrm{w} / \mathrm{v})$ yeast extract and $0.2 \%$ $(\mathrm{w} / \mathrm{v})$ starch. Incubation was at $37^{\circ}$. Cellophan disks and the microcultures which they bore were removed at intervals and stained by the phosphomolybdic acid + methyl green method for cell-walls; they were mounted in water for observation. The unusual forms illustrated here were obtained upon only two occasions and could not be controllably repeated.

\section{RESULTS \\ Apparent anastomosis in Streptomyces}

Plate 1, figs. 1-6, show the development of a branching mycelial system, adherent to the cover-glass in the air space surrounding the agar, during a period of $4 \mathrm{hr}$. (see legend). Growth was very rapid at certain points. In this field events which may or may not represent fusion between branches of the mycelium can be seen occurring at three points. The resulting forms are like those shown by Dickenson \& Macdonald (1956) who considered that fusion 
occurred at such sites. At none of the three contact points in Pl. 1, figs. 1-6, can cellular fusion be definitely seen; the contact areas more closely simulate the appressoria of fungi than the anastomoses of Streptomyces as illustrated by Gregory (1956). It is interesting to note that in Pl. 1, fig. 6, at the contact area on the extreme left, one of the two mycelial branches seems to have degenerated, leaving the other member of the pair quite sound. Similar unilateral degeneration was observed upon other occasions. This observation can be interpreted either as indicating the absence of cell fusion, or as the aftermath of the transfer of cell contents from one branch to the other. The apparent degeneration might also be an artifact, e.g. loss of adherence to the coverglass. No apparent changes in the form of the mycelium (e.g. swelling) were observed as a result of these anastomoses, if such they be. Sporulation occurred in the microcultures but always in the centres of colonies where observation was not possible.

It appears certain that mycelial branches do not actively avoid contact with each other. The detection by Stuart (1959) of a 'mucoid cementing substance between substrate hyphae' is of interest in this relationship.

In Pl. 1, fig. 7, a branching and anastomosing system of the type illustrated by Gregory (1956) is shown. Here there does appear to be true anastomosis at least at four points. This figure is also interesting as an example of the way in which Streptomyces strains characteristically branch from alternate sides of the main mycelial filament. This may be compared with the basically similar mode of growth seen in Leptotrichia dentium (Baird-Parker \& Davis, 1958) and sometimes in Nocardia spp. The branches in Streptomyces normally arise very near the cross septa which divide the mycelium into cells (see Stuart, 1959); the septa are not shown in $\mathrm{Pl} .1$, fig. 7 .

\section{An unusual cytological appearance in Nocardia asteroides}

Plate 1, figs. 8 and 9, are included because they not only illustrate a very unusual type of structure, but also resemble very closely the large irregular masses which Gregory (1956) illustrated in Streptomyces. In both cases the deeply staining masses occurred only at the extremities of the mycelia and it seems reasonable to conclude that they represent the extruded content of the mycelium. The extrusion may have occurred as a result of inefficient cell-wall synthesis at the growing points under conditions of inadequate nutrition. Whether these cytoplasmic masses are equivalent to the 'protoplasts' (? spheroplasts) obtained by Bradley (1959) by using lysozyme, it is not possible to say. However, if this were the case it might explain the observation by previous workers of large 'spore-like' bodies or even 'initial-cells' in Streptomyces, some of which regenerate mycelium.

\section{REFERENCES}

Baird-Parker, A. C. \& Davis, G. H. G. (1958). The morphology of Leptotrichia species. J. gen. Microbiol. 19, 446.

Baldacci, E., Gilardi, E. \& Amici, A. M. (1956). Il ciclo di vita degli Attinomiceti osservati al microscopio elettronico. G. Microbiol. 6, 512. 
Journal of General Microbiology, Vol. 22, No. 3

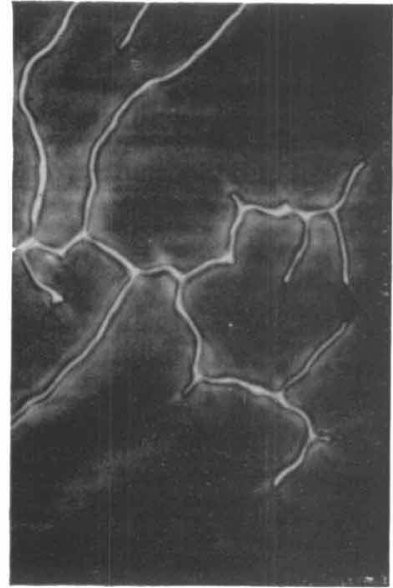

1

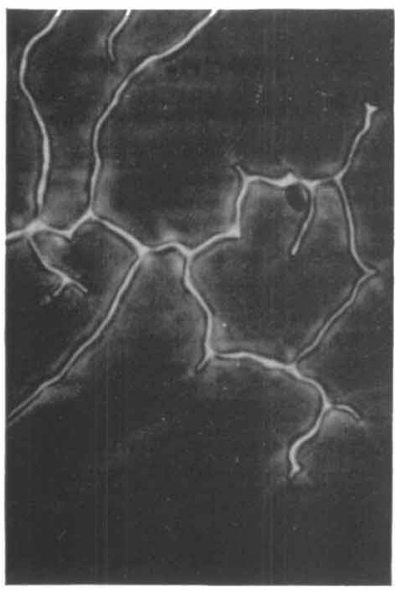

4

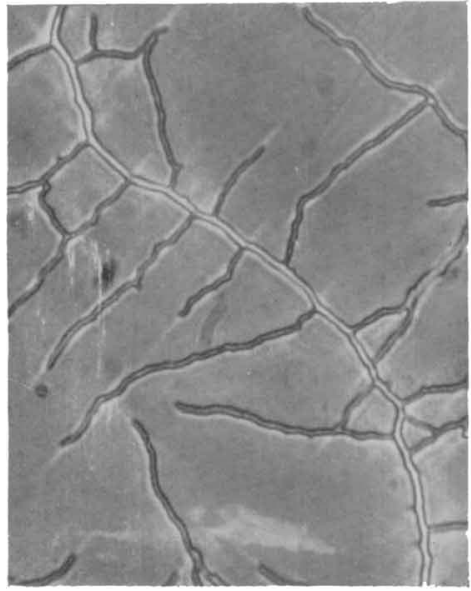

7

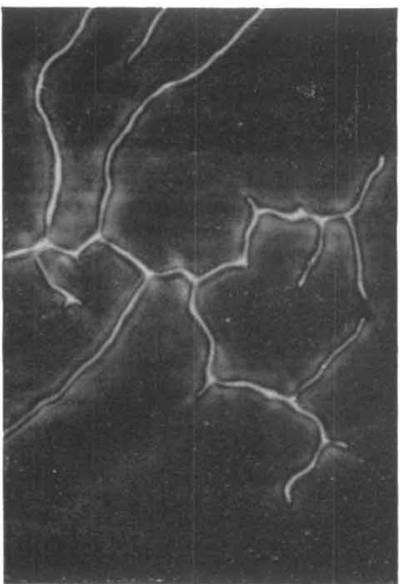

2

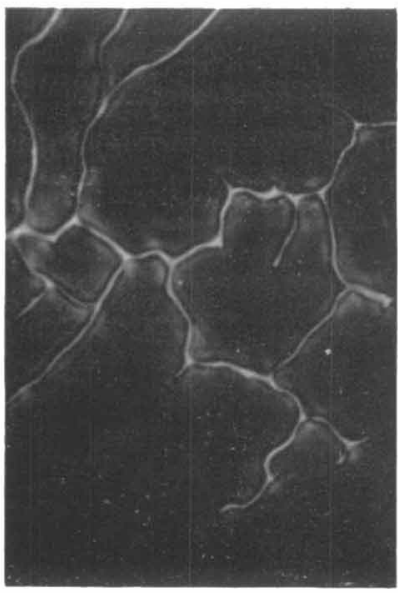

5

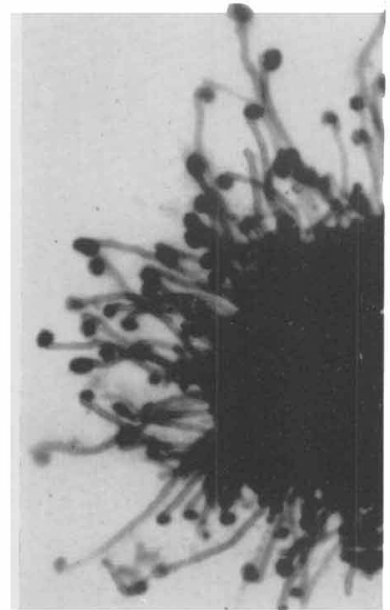

8

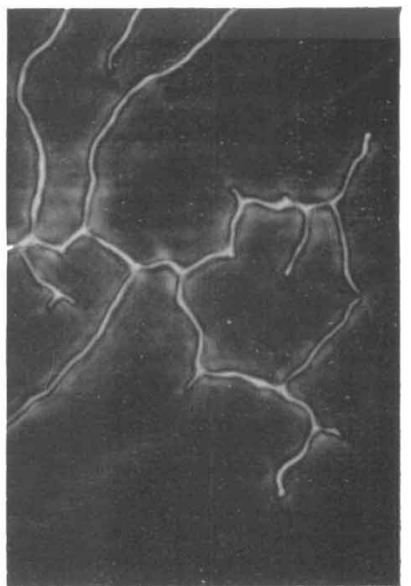

3

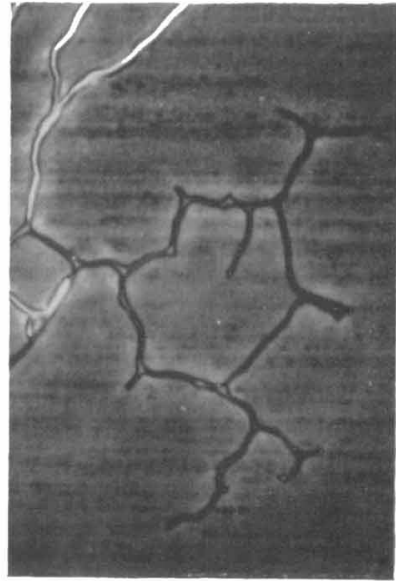

6

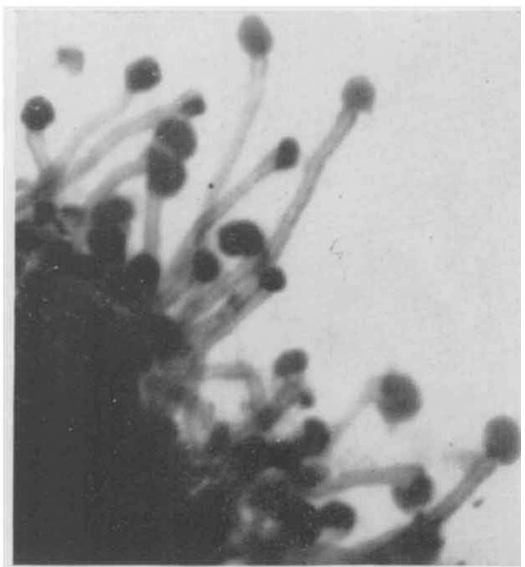

9

G. H. G. Davis-Morphology of Streptomyces. Plate 1

(Facing $p$. 742) 
Bisset, K. A. (1955). The Cytology and Life-history of Bacteria, 2nd ed. Edinburgh: Livingstone.

BradLeY, S. G. (1957). Heterokaryosis in Streptomyces coelicolor. J. Bact. 73, 581.

Bradley, S. G. (1958). Mechanisms of 'vegetative hybridisation' in Streptomyces. J. gen. Microbiol. 18, 591.

Bradley, S. G. (1959). Protoplasts of Streptomyces griseus and Nocardia paraguayensis. J. Bact. 77, 115.

Bradley, S. G. \& Lederberg, J. (1956). Heterokaryosis in Streptomyces. J. Bact. $72,219$.

Carvajal, F. (1946). Studies on the structure of Streptomyces griseus. Mycologia, 38, 587.

Davis, G. H. G. (1959). Morphology and bacterial taxonomy. Lab. Pract. 8, 161.

Dickenson, P. B. \& Macdonald, K. D. (1955). An electron microscope examination of the initial cell stage in Streptomyces spp. J. gen. Microbiol. 13, 84.

Erikson, D. (1949). The morphology, cytology and taxonomy of the actinomycetes. Annu. Rev. Microbiol. 3, 23.

ErIKson, D. (1955). Loss of aerial mycelium and other changes in Streptomycete development due to physical variations in cultural conditions. J. gen. Microbiol. 13, 136.

Gregory, K. F. (1956). Hyphal anastomosis and cytological aspects of Streptomyces scabies. Canad. J. Microbiol. $2,649$.

KuIENEBErger-Nobes, E. (1947). The life-cycle of sporing Actinomyces as revealed by a study of their structure and septation. J. gen. Microbiol. 1, 22.

McGregor, J. F. (1954). Nuclear division and the life-cycle in Streptomyces sp. J. gen. Microbiol. 11, 52.

Sermonti, G. \& Spada-Sermonti, I. (1956). Gene recombination in Streptomyces coelicolor. J. gen. Microbiol. 15, 609.

Stuart, D. (1959). Fine structure of the nucleoid and internal membrane systems of streptomyces. J. Bact. 78, 272.

\section{EXPLANATION OF PLATE}

Figs. 1-6. Streptomyces sp. in microculture by phase-contrast microscopy. $\times c .1500$. Observed after $c .48 \mathrm{hr}$. incubation at $28^{\circ}$. Figs. 1-6 show the developments in a single field during $240 \mathrm{~min}$. Fig. 1, zero time; fig. 2, $15 \mathrm{~min}$.; fig. 3, $30 \mathrm{~min}$; fig. 4, $40 \mathrm{~min}$; fig. 5, 120 min.; fig. 6, 240 min.

Fig. 7. Streptomyces sp. in microculture by phase-contrast microscopy. $\times c .1500$. Not the same culture as that shown in figs. 1-6, but grown under similar conditions.

Fig. 8. Part of microcolony of Nocardia asteroides on surface of cellophan, $24 \mathrm{hr}$., stained with phosphomolybdic acid + methyl green.

Fig. 9. Part of colony shown in Fig. 8 at higher magnification. $\times c .2000$.

(Received 10 December 1959) 